\title{
HESS Opinions: Hydrologic predictions in a changing environment: behavioral modeling
}

\author{
B. Schaefli ${ }^{1,2}$, C. J. Harman ${ }^{3}$, M. Sivapalan ${ }^{2,3,4}$, and S. J. Schymanski ${ }^{5}$ \\ ${ }^{1}$ Laboratory of Ecohydrology (ECHO), School of Architecture, Civil and Environmental Engineering (ENAC), \\ Ecole Polytechnique Fédérale de Lausanne (EPFL), Lausanne, Switzerland \\ ${ }^{2}$ Water Resources Section, Delft University of Technology, Delft, The Netherlands \\ ${ }^{3}$ Department of Geography, University of Illinois at Urbana-Champaign, Urbana, USA \\ ${ }^{4}$ Department of Civil and Environmental Engineering, University of Illinois at Urbana-Champaign, Urbana, USA \\ ${ }^{5}$ Max Planck Institute for Biogeochemistry, Jena, Germany
}

Received: 17 September 2010 - Published in Hydrol. Earth Syst. Sci. Discuss.: 5 October 2010

Revised: 2 February 2011 - Accepted: 18 February 2011 - Published: 24 February 2011

\begin{abstract}
Most hydrological models are valid at most only in a few places and cannot be reasonably transferred to other places or to far distant time periods. Transfer in space is difficult because the models are conditioned on past observations at particular places to define parameter values and unobservable processes that are needed to fully characterize the structure and functioning of the landscape. Transfer in time has to deal with the likely temporal changes to both parameters and processes under future changed conditions. This remains an important obstacle to addressing some of the most urgent prediction questions in hydrology, such as prediction in ungauged basins and prediction under global change. In this paper, we propose a new approach to catchment hydrological modeling, based on universal principles that do not change in time and that remain valid across many places. The key to this framework, which we call behavioral modeling, is to assume that there are universal and time-invariant organizing principles that can be used to identify the most appropriate model structure (including parameter values) and responses for a given ecosystem at a given moment in time. These organizing principles may be derived from fundamental physical or biological laws, or from empirical laws that have been demonstrated to be time-invariant and to hold at many places and scales. Much fundamental research remains to be undertaken to help discover these organizing principles on the basis of exploration of observed patterns of landscape structure and hydrological behavior and their interpretation as legacy effects of past co-evolution of climate, soils, topography, vegetation and humans. Our hope is that the new behavioral modeling framework will be a step forward to-
\end{abstract}

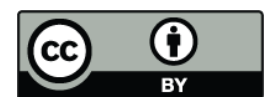

Correspondence to: B. Schaefli (bettina.schaefli@epfl.ch) wards a new vision for hydrology where models are capable of more confidently predicting the behavior of catchments beyond what has been observed or experienced before.

\section{Introduction}

\subsection{Hydrologic change - the prediction challenge}

The world is presently experiencing rapid and large scale modifications of the land surface (e.g. deforestation, urbanization) and changes to the climate. In the context of this ongoing global change, understanding and predicting the related hydrologic changes is one of the most urgent questions that hydrologists face today (Barnett et al., 2008; Stonestrom et al., 2009; Blöschl and Montanari, 2010). Perhaps the greatest challenge comes from the fact that the consequences for hydrology will arise from both changes in the forces acting on the landscape (climate, land management), and from the way change is transmitted through the various associated systems and subsystems. As a result, both the ecosystem structure (e.g., vegetation patterns, drainage network, soil properties) and its hydrologic response (e.g., water balance, extremes) undergo modifications. For example, in Alpine catchments where the glaciers are gradually disappearing due to a warmer climate predicting the consequences for discharge (e.g. Horton et al., 2006; Huss et al., 2008) involves predicting how fast and to what extent the ice may melt, how vegetation may evolve on the newly icefree surfaces, and how the rainfall-runoff behavior regime is modified in the "new" catchment that emerges as a result. As the ice melts away in these catchments, weathering and new erosion processes emerge on the moraines exposed to

Published by Copernicus Publications on behalf of the European Geosciences Union. 
the atmosphere, vegetation succession occurs, new vegetation emerges and accesses different soil moisture compartments, soil structure as well as soil biology changes as a result of modified hydric conditions. In short, all biotic and abiotic components of the ecosystem are undergoing simultaneous, interdependent changes.

\subsection{A challenge to the status quo}

These interdependent changes present a fundamental challenge to the way predictions are typically made in catchment hydrology. The most common approach adopted in presentday change predictions is the adoption of likely or alternative future "scenarios" regarding climate, land cover or land use, and other hydrological parameters (Mahmoud et al., 2009). The structure of the catchment ecosystem is considered essentially as fixed, with climate as an exogenous forcing (akin to solving a boundary value problem). In the Alpine example above, the future scenarios could specify the extent of glaciers and of forested areas under climate change, chosen to represent likely future conditions in a seemingly plausible way. A typical approach to assigning plausible future values to model parameters and forcings is the use of external (not coupled) model outputs (e.g., global climate models, land use evolution models) or the use of expert judgment. The likely impacts of these change scenarios on hydrological responses are then evaluated using models developed for the present or past conditions.

The following two examples illustrate the scenario-based approach to hydrologic prediction. Zierl and Bugmann (2005) simulated the future hydrologic responses of Swiss Alpine catchments under global IPCC (Intergovernmental Panel on Climate Change) land use change scenarios using a physically-based ecohydrological model. They decreased forest cover in valley bottoms and increased forested areas close to the timberline without, however, considering the evolution of the timberline itself due to projected climate change. Schaefli et al. (2007) created future scenarios of glacier surface area using an empirical relationship with snow accumulation area, and simulated the resulting precipitation-runoff transformation with a conceptual hydrological model. Apart from updating the glacier surface, all other model parameters, such as those relating evapotranspiration to soil moisture were kept unchanged, even though in reality the vegetation composition is highly likely to change.

If we attempt to predict long-term hydrologic change where both the landscape structure and the hydrologic response evolve, feeding back on each other, then past response alone cannot be a sufficient guide to future response, and current hydrologic behavior (including both landscape structure and hydrologic response) cannot readily be extrapolated to predict future behavior, such as through the use of assumed future change scenarios. Such scenario-based predictions can only be seen as informed guesses, producing rough estimates of possible future conditions, accounting only partially for likely directions of natural and anthropogenic ecosystem evolution.

An alternative approach is to broaden the prediction problem to the coupled modeling of the landscape structure, the climatic drivers and the hydrologic response, including the feedbacks resulting from their co-evolution. This approach has long been recognized in climate and earth system sciences, and has motivated the development of several fullycoupled, highly detailed, physically-based land-atmosphere or earth system models that aim to include all relevant biological, geomorphologic, pedologic, hydrological and meteorological processes and appropriate initial and boundary conditions (e.g. Doherty et al., 2000; Levis et al., 2004). In this type of model, the ecosystem (both structure and response) evolves as a result of interactions and feedbacks between all the encoded (hydrological, land forming and life sustaining) processes.

The trajectory of ecosystem evolution in these highly complex coupled models depends very much on the realism and accuracy of the various process descriptions and the associated parameter values. Under these circumstances, what confidence do we have that such predictions turn out to match reality, or even come close to what might actually happen in the future? The descriptions of individual processes, process interactions and feedbacks are intrinsically imprecise and uncertain, and may highly depend on initial conditions, which are also possibly unknown.

\subsection{A way forward}

In this paper, we present a possible new approach to hydrologic predictions, which we call behavioral modeling. This new approach presents an elegant way forward to critically learn from observations of past behavior to predict future behavior in probabilistic terms, i.e. to use understanding of past behavior to choose amongst many possible trajectories of future system evolution. The rationale of this new approach, which will be elaborated in more detail in the remainder of this paper, can be summarized as follows: The current structure of an ecosystem is a legacy of its historical evolution, and therefore contains information about that evolution, which we can potentially summarize in terms of (an) organizing principle(s). This principle, in turn, can potentially be used to develop a predictive framework that combines it with observed data and any other prior knowledge. In this sense, the organizing principle acts as a "likelihood function": it tells us which, among all physically possible outcomes (given conservation laws of mass, momentum and energy, as well as local constraints), are the most probable ones.

Section 2 of this paper elucidates the rationale and fundamental assumptions of the proposed approach. We then discuss the nature of the organizing principles in more detail (Sect. 3), drawing on examples in the literature where these principles have already been identified and applied. In 

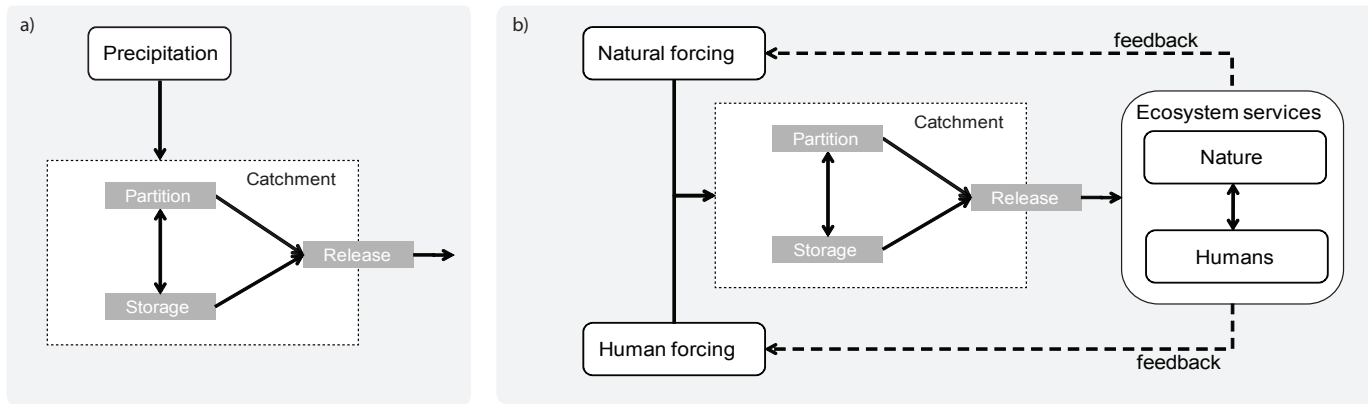

Fig. 1. (a) The catchment and its function, viewed as a system with fixed structure and precipitation as exogenous forcing (adapted from Wagener et al., 2007, with the permission of the authors); (b) the catchment as part of an evolving ecosystem, which provides services and feeds back on the human and natural forcing.

Sect. 4 we describe the practical application of the approach and its relationship to established modeling approaches and other usages of the term behavioral in hydrology. We use examples to illustrate the major challenges involved in developing such a new modeling framework, and the open science questions that need to be addressed as we proceed in this direction (Sect. 5). We conclude (Sect. 6) by providing a perspective on possible ways forward to achieve these goals.

\section{Predicting hydrologic change: behavioral modeling}

\subsection{The structure problem}

Hydrologic predictions at the catchment scale are hampered by what we call here the "structure problem": the difficulty to provide a mapping between the catchment's bio-geomorphic structure exerting a dominant control on the hydrological processes and the necessary model structure to predict these processes (i.e., to extrapolate them in space or in time).

This well-known and often discussed problem (e.g. Beven and Freer, 2001; Sivapalan, 2003) manifests itself differently for different model types. Prediction methods of the bottom-up type rely on physical descriptions of all relevant processes; detailed knowledge of the topology/connectivity of surface and subsurface flow paths is crucial to predicting storage, release and redistribution of water, dissolved mass, and energy within the system. Such bottom-up models suffer from the fact that current technologies do not enable us to observe these structures and associated hydrologic processes in situ everywhere.

An alternative, top-down, approach is to infer dominant catchment structures from data by attempting to reproduce observed integral responses, such as residence time distributions of water leaving the catchment as expressed in the form of the hydrograph - or in the form of tracer breakthrough curves. Due to their integral nature, such signals are of "low dimension", and the inference of model structures from such integral catchment responses suffer from "equi- finality" and uncertainty: several types of model structures chosen to reflect the bio-geomorphic structures in the landscape may yield the same integral response. This is a serious drawback when one considers the fact that in a changing environment the catchment architecture can be expected to also evolve due to changes in the system boundary conditions.

\subsection{Structure and organization in catchments}

Many researchers in the hydrologic community have come to the realization that a possible way to overcome both "structure" problems mentioned above is to add an intermediate level of abstraction that helps connect landscape structure to model structure, for example using the concept of hydrologic ecosystem functions, which is receiving increasing interest in hydrology (Sivapalan, 2005; Wagener et al., 2007).

Following Black (1986), Wagener et al. (2007) define the hydrologic functions of a catchment as consisting of partitioning, storage (retention) and release of water (Fig. 1a), and suggest that we need something more than mere small scale process descriptions to fully capture these essential and universal functions. This is because they arise as emergent behaviors from the natural organization of the catchment structure, linked by interactions and feedbacks to other land forming and life sustaining processes occurring within the ecosystem (e.g. Lin and Chen, 2006; Sidle and Onda, 2004; Paola et al., 2006; Kumar, 2007), including the role of humans (Fig. 1b).

This complex interplay between biotic and abiotic processes shapes the constantly evolving landscape; whatever properties it has today are the legacy effects of the history of its evolution. The structure of the landscape (e.g. vegetation patterns, river networks, soil catena) suggests that these interactions of climatic, geomorphic, pedological, biological and hydrologic processes is not unorganized but indeed leads to specific, identifiable patterns (e.g. Rietkerk and van de Koppel, 2008). The mechanisms underlying the observed patterns and functions of catchments and associated ecosystems and their connection across time, space and scale are 
the subject of intense research (e.g. Levin, 1992; RodriguezIturbe et al., 1992a; Thomas, 2001; Gisiger, 2001; Sivapalan, 2005), and a range of models that reproduce observed patterns and feedbacks are available (see e.g. Borgogno et al., 2009; Rodriguez-Iturbe et al., 2007). Saco et al. (2006), for example, present a model that, in water-limited ecosystems, reproduces observed patterns of vegetation, runoff, erosion and their redistribution, and the evolution of microtopography. Conversely, it is reasonable to expect that observable patterns of vegetation and micro-topography contain valuable information and may provide insights into the interactions and feedbacks between the water flow and evolutionary land forming and ecological processes that they emerge from (e.g. Grimm et al., 2005).

\subsection{Using organizing principles to constrain models}

From this perspective, it is tempting to think that the organized patterns that we see in the landscape could be translated into certain principles that may underpin these emergent patterns and encapsulate the nature of system evolution, in the future as well as in the past.

In the words of Rinaldo et al. (2006), "nature works through imperfect searches for dynamically accessible optimal configurations". If we can discover and summarize the underlying principles in terms of rules or governing laws (Paik and Kumar, 2010), we could mimic this search in our models and identify plausible (future) system states respecting these principles as well as any other boundary conditions or constraints that may apply. We call these governing laws "organizing principles" (a term that is becoming increasingly popular in the literature, e.g. McDonnell et al., 2007; Wagener et al., 2010), and the plausible states "behavioral" - in analogy to the usage of this term in systems theory, where "behavioral" designates a subset of all theoretically possible dynamic system outcomes that is actually observed. Polderman and Willems (1998) give the example of planetary orbits to illustrate this concept. Since the time of Kepler we know that they are elliptic. The general equation describing the movement of two bodies mutually attracted by gravitation would also allow hyperbolic paths but they would not be "behavioral", and are eliminated. A hydrological example can be found in the work of Ridolfi et al. (2006): they describe a riparian water table - vegetation feedback system that theoretically has two stable states, complete vegetation cover or complete absence of vegetation, but the non-vegetated state is rarely observed in nature, i.e. therefore it is not behavioral.

As mentioned earlier, the evolution of a catchment ecosystem could, in theory, be predicted by modeling all relevant process interactions with suitably complex models. However the uncertainty in the model structure and parameters limits our ability to make reliable predictions with such models. An infinite number of trajectories of system evolution may be possible in the future, and there is a clear need to discriminate amongst these and choose only those that are plausible.
If we adopt a priori the organizing principle that encapsulates or drives some of these interactions, we can then account directly for their joint effect on the overall system behavior by adjusting the model structure and parameters so as to respect this organizing principle.

\section{Identifying organizing principles}

An organizing principle may be seen as the answer to the question: "In a landscape where every component is permanently changing, is there some principle that nevertheless persists and continues to manifest itself in the evolving features of this dynamic system?" This general definition is indeed very broad and leaves space for a large range of potential organizing principles that either reflect the causes of evolution or the resulting signatures (for a short discussion of these points of view, see Paik and Kumar, 2010).

The use of organizing principles is predicated on the idea that there are certain configurations of the system that are more likely to occur than others. These "stable states" should not be confused with the notion of equilibrium or steadystate. Environmental systems are non-equilibrium systems by definition, and moreover are almost never observed in a "steady-state".

Two broad classes of organizing principles can already be found in the hydrologic literature: optimality principles and empirical patterns.

\subsection{Optimality principles}

Optimality modeling is a technique which first became popular in behavioral ecology to predict the behavior of animals given all factors and constraints facing them (see, e.g. Krebs and Davies, 1993). A recent example is the prediction of bird migration routes on the basis of optimal trade-offs between travel time and energy-use (Vrugt et al., 2007).

A special issue of Philosophical Transactions of the Royal Society, B-Biological Sciences, edited by Kleidon et al. (2010), provides overviews of physical concepts underpinning optimality, such as maximum entropy production (Kleidon et al., 2006; Kleidon and Schymanski, 2008; Ozawa et al., 2003), minimum energy expenditure (RodriguezIturbe et al., 1992b; Rinaldo et al., 1992) or Helmholtz free energy dissipation (Zehe et al., 2010). Paik and Kumar (2010) discuss a range of optimality principles that can be used to interpret observed landscape patterns or to predict land forming processes and the resulting patterns.

In the case of biotic systems, optimality principles can be formulated on the basis of established biological laws, such as Darwin's theory of evolution. A listing of evolutionary organizing principles in plant sciences can be found in the review by Schymanski et al. (2009a). The most well known example in hydrology is the use of ecological optimality principles by Eagleson (Eagleson, 1982, 1978; Eagleson and 


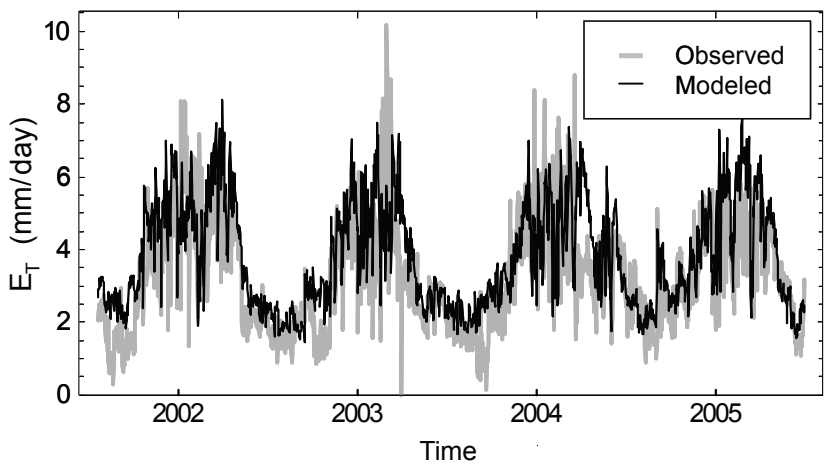

Fig. 2. Result of an optimality based modeling framework (from Schymanski et al., 2009b): observed and modeled daily evapotranspiration rates. The model simulates the vegetation that optimizes the net carbon profit given an observed semi-arid climate in Australia.

Tellers, 1982) who focused on net primary production. In more recent ecohydrological studies, we have seen the introduction of several other alternative organizing principles such as the maximization of water use, the minimization of water or oxygen stress (e.g. Brolsma and Bierkens, 2007; Marani et al., 2006b; Porporato et al., 2001; Rodriguez-Iturbe et al., 1999; Caylor et al., 2009), and the maximization of net carbon profit: Schymanski et al. $(2007,2009 b)$ simulated the most probable vegetation cover in catchment ecosystems as the one that maximizes the long-term net carbon profit for a given climate, subject to local constraints. They obtained good correspondence between transpiration fluxes observed under the given climate and the corresponding simulated flux for the most probable vegetation cover (see Fig. 2).

\subsection{Empirical patterns}

The above optimality-based organizing principles result from a priori knowledge and assumptions about the underlying physical and ecological principles. However, we can also formulate organizing principles that are empirical, i.e. based on the patterns of the behavior of natural systems observed at many places, scales or moments. Such empirical principles or laws can be used for predictions only after they have been extensively shown to be time-invariant and valid at many places and scales.

A good example of such an empirical organizing principle in hydrology is the Budyko curve (Budyko, 1984), which is a widely known and accepted universal pattern related to the climate dependence of the annual water balance. In the Budyko diagram (Fig. 3), in theory, the ratio of annual evapotranspiration to precipitation can take on any value below the straight line envelopes, and yet values near the empirical Budyko curve are deemed the most probable, or in other words behavioral. In this sense, the Budyko curve is a potentially useful concept to discriminate between likely and unlikely catchment annual water balance responses. For example, Li (2010) used the Budyko curve to discriminate between unlikely and likely parameter combinations (climate, soils and topography) for a physically-based, high resolution, spatially distributed hydrological model.

Hydraulic geometry relations can be seen as a widely-used form of a behavioral model. An early example is Lacey (1930) who found a simple equation relating the width of a natural channel at bank-full discharge to the square root of flow. As pointed out by Savenije (2003), many authors have confirmed this simple formula without being able to give a physical (causal) explanation. Savenije suggested that Lacey's formula emerges from the "bed-shaping flow velocity that has just sufficient power to lift the bottom material to the natural levee". The existence of such relationships implies that there may indeed be organizing principles that are useful for making predictions about whole system behavior at ecosystem level, which have not yet been shown to reflect a classical (i.e., physical or biological) law or related optimality principle.

\subsection{Use of modeling to develop organizing principles}

As the evolution of natural systems is often very slow, we can rarely observe it. Therefore, a promising approach is to translate the observed behavior into a model and to let the model shed light on the evolution and on potential stable states. An example can be found in (Wong, 2008): Analyzing the effect of overland flow regime on detention storage, Wong found that the dominant flow regime in nature is the one that provides maximum flood attenuation. Another example is the work of Ridolfi et al. (2006) (see also Sect. 2.3): They formulated a simple model of water table - vegetation dynamics in riparian zones and identified several theoretical stable states depending upon the initial water table depth. They argued that one of the stable states (corresponding to absence of vegetation) is rarely observed in nature and discuss how to make use of their results to quantify ecosystem resilience.

Such ecosystem resilience could itself be used as an organizing principle to build predictive models. In fact, resilience is a classical landscape sensitivity concept that designates the likelihood of a change, which is widely used in geomorphology and in ecology (e.g. Usher, 2001). In ecology, the sensitivity concept takes on different forms, such as elasticity, extinction risk, persistence, population viability, resilience, resistance, or turnover time (Miles et al., 2001). These results point towards potentially new experimental and modelling approaches that can be adopted for discovering new organizing principles, as articulated by Kleinhans et al. (2010). 


\section{Behavioral modeling in practice}

\subsection{How do we build behavioral models?}

Building a hydrologic prediction model within the behavioral modeling framework involves the following steps: (i) understand current or potential stable system states resulting from the co-evolution of interacting processes; (ii) summarize this understanding in some time-invariant organizing principle useful for hydrologic prediction at many places, scales and times; (iii) build a predictive model that can simulate a range of different system behaviors; (iv) use the organizing principle to identify the most probable system behavior, i.e. to identify the most appropriate model parameterization for a given case study; (v) validate or falsify the model with available local observations.

Understanding and identifying stable system states and organizing principles (Step i and ii), from observed data or models requires of course, much further research along the lines of Sect. 3. The development of predictive models (Step iii) can largely be based on existing modeling concepts and Step iv) on existing search algorithms (with the objective function reflecting the organizing principle, see the example hereafter).

The final step of model validation and falsification is an essential component of the behavioral modeling framework. It is this step that ensures that a behavioral model is both consistent with local observations and with the proposed organizing principle(s); confronting the model outputs with observed data can truly falsify the model - since a model based on a wrong organizing principle is unlikely to reproduce the observations, while a model that reproduces the observations for the wrong reasons is unlikely to satisfy the organizing principle(s).

\section{An Example of a behavioral model}

The Vegetation Optimality Model (VOM) developed by (Schymanski et al., 2009b) represents an illustration of the development of a behavioral model. This development commenced with the formulation of "maximization of the net carbon profit (NCP)" as the likely organizing principle that underpins the adaptation of vegetation to its environment (Schymanski, 2007; Schymanski et al., 2007). In order to implement this principle as the foundation of a falsifiable hypothesis, the authors identified key degrees-of-freedom that vegetation has in its adaptation to the environment, and quantified the associated costs and benefits so as to be able to compute the NCP.

These degrees-of-freedom chosen included the fractional vegetation cover, the number of foliage layers and the photosynthetic capacity in each foliage layer; the stomatal conductance was prescribed based on measurements. The associated costs referred to construction and maintenance costs

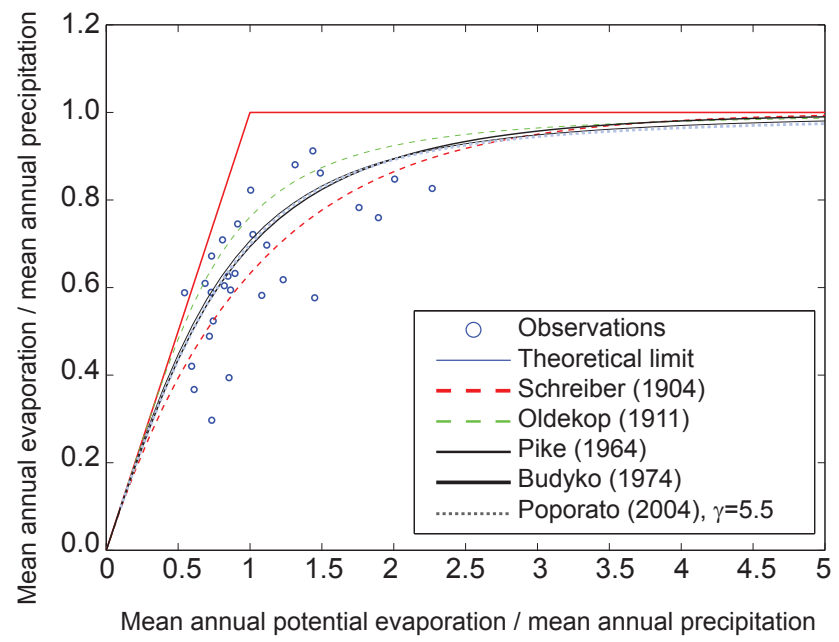

Fig. 3. From Gerrits et al. (2009), reproduced with the permission of the authors: different representations of the Budyko curves and some observations. The 1:1 limit expresses the limitation by available energy, and the horizontal limit expresses the limitation by available water.

of leaf area and maintenance respiration related to the photosynthetic apparatus. The state of each of these possible adaptations was then identified by searching for the configuration that yields maximum NCP.

The $\mathrm{CO}_{2}$ and evaporation fluxes predicted by the resulting model where then used to test the NCP hypothesis by confronting the predictions with site-specific observations at a savanna site. This test resulted in a hypothesis falsification during the dry season, but not during the wet season (Schymanski et al., 2007), which led to the conclusion that the costs for water uptake and deep roots might be limiting the canopy cover in the dry season.

Water uptake and the associated costs and benefits were included in an extended version of the VOM, where the relevant parameters were optimized using the well-known Shuffeld-Complex Evolution algorithm (Duan et al., 1994), and maximum NCP as objective function. This led to a satisfactory reproduction of the rooting depth, canopy cover dynamics and seasonal fluxes of $\mathrm{CO}_{2}$ and water vapor over several years at the same savanna site (Schymanski et al., 2009 b). Clearly, the reduction of the need for calibration by the inclusion of an organizing principle resulted in a falsifiable model. From the partial falsification in the first step (Schymanski et al., 2007), the authors learned enough to construct a model with a clear potential for multivariate prediction (Schymanski et al., 2009b). The utility of the maximum NCP principle for reducing the need of model calibration was also demonstrated separately for simulating canopy conductance (Schymanski et al., 2008a) and root water uptake (Schymanski et al., 2008b). 

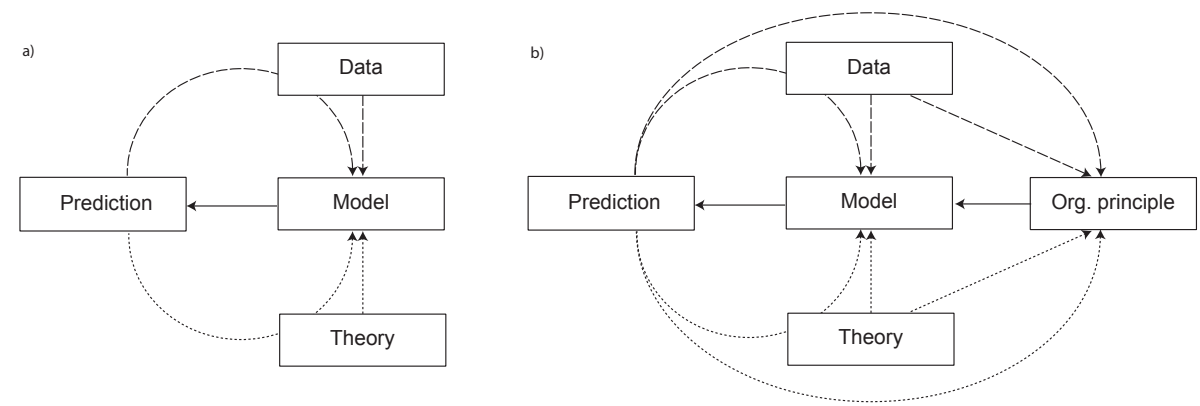

Fig. 4. (a) Classical bottom-up (dotted lines) and top-down (dashed lines) model development approach (inspired from Sivapalan, 2005); (b) new behavioral framework.

\subsection{Relation to existing modeling approaches}

Traditional prediction models in catchment hydrology are developed using either a bottom-up or a top-down approach (Sivapalan, 2005, see also Fig. 4a). As illustrated in Fig. 4b, the behavioral modeling framework can be seen as an extension of this traditional framework, where the organizing principle is used to identify the most appropriate model (structure). Because a model of hydrologic change must account for structure forming and life sustaining processes in the landscape, one would normally expect them to be more complex and multi-dimensional than traditional hydrological models. The use of organizing principles, however, contributes to model parsimony: as Marani et al. (2006a) state in the context of developing a coupled, predictive model of vegetation and geomorphology for tidal ecosystems, the key is the "identification of simplified formulations of the relevant biophysical interactions, yet retaining their essential dynamics". The organizing principle, in turn, would have been previously identified based on theory and data. For example, the Budyko curve, as an empirical organizing principle, results from theory (envelop lines), as well as from observed data. As in a traditional modeling framework, the model predictions are compared to theory and to observed data to validate the modeling assumptions.

On the basis of the above discussion, one may be tempted to think that the development of behavioral models is way too far into the future. In reality, though, many behavioral models are already in place although they are not yet called that. As example, we would like to present the results of a modeling study (representing the bottom-up approach) that, in our view, is just a small step away from using organizing principles for hydrologic predictions.

Hwang et al. (2009) use a complex physically-based model (the RHESSys model Band et al., 1993; Tague and Band, 2004) to investigate whether the observed ecosystem patterns in a fully forested catchment of the Southern Appalachian Mountains correspond to some optimal configuration under the local climate and soil conditions. They asked the question whether the catenary sequence of ecosystem patches maxi- mizes a catchment scale vegetation property such as Net Primary Production (NPP). Hwang et al. (2009) first calibrated the hydrological model parameters to yield maximum correspondence between observed and simulated daily runoff. They then varied the average rooting depth and the spatial arrangement of rooting depths (i.e., from increasing in hillslope direction to uniform and then to decreasing in the hillslope direction) to yield maximum correspondence between observed and simulated above ground vegetation (in terms of leaf area index). Subsequently, they showed that the same rooting depth distribution parameters that led to an optimal correspondence between simulated and observed runoff also maximizes catchment scale NPP (compare Figs. 9b and 11a of Hwang et al., 2009).

In the discussion of their results Hwang et al. (2009) argue that the observed vegetation gradients do correspond to some optimal state of system-wide carbon uptake (Hwang et al., 2009, Sect. 5.1). From a behavioral modeling perspective, we understand this to mean that they have found evidence that maximization of NPP can be used as an organizing principle to make predictions about spatial vegetation patterns and coupled ecohydrologic response. In other words, their results suggest that they could calibrate their detailed process model by simply maximizing NPP, i.e. to ensure that the model satisfies the identified organizing principle. Then, the simulated and observed patterns could be used to validate or falsify the assumptions in the model.

This offers some new perspectives for change predictions too: for example, if they were to investigate system behavior under changed climate, they could directly infer the future vegetation patterns along with the future hydrologic regime through invoking the organizing principle alone, assuming that it is both universal and time invariant. This, in our view, would represent a considerable advance over scenario-based predictions, i.e., simply feeding assumed climate change scenarios into a present-day hydrological model. 


\section{Relation to other "behavioral model" concepts}

Hydrological modeling has a long tradition of parameter estimation and model identification. In this context, Beven and Binley (1992) shaped the usage of the term "behavioral parameter sets" for sets that, within a chosen model structure, give acceptable reproductions of the observed behavior. This usage goes back to Hornberger and Spear (1980) who suggested " $(. .$.$) that the result of any simulation using a model$ can (...) be classified as exhibiting either 'the behavior' or 'not the behavior' (of the system)" (Hornberger and Spear, 1980 , p. 30) and led to the expression "behavioral model" (Beven, 2006).

Just as in our proposed framework, Beven's use of the concept "behavioral" designates, but in the traditional model development context, a subset of all possible models that is plausible given the historical behavior of the studied system. The identification of such plausible models involves, as a starting point, the rejection of models that do not respect basic physical principles and conservation laws. Of course, these are by no means sufficient to constrain a prediction model, due to our inability to know the boundary conditions and parameters associated with our boundary value problem; a subsequent and far more important selection step is, thus, based on a comparison of the simulated variable (e.g. discharge) to observed values (time series) of this target variable to select those parameter sets or model structures that are behavioral. This selection is based on a performance measure that can be either a classical sum-of-squared error measure or any other distance measure (see, e.g. Schaefli and Zehe, 2009). The retained models are, thus, the ones that best mimic historical records, at the place of interest, of the variable to be predicted.

Beven's notion of "behavioral models" is fundamentally different from our definition of "behavioral models based on organizing principles". In our case, behavioral modeling uses a priori knowledge and/or historical behavior (in many places) to propose or derive an organizing principle to help identify behavioral models at a particular place. The method of identification depends on the type of organizing principle. In the case of optimality principles, a behavioral model simply maximizes or minimizes an objective function that best represents the organizing principle and that can be estimated from a system output. The fundamental difference to Beven's notion lies in the fact that in our definition of behavioral modeling, the identification of behavioral models involves employing deeper and general insights into the system dynamics and explicitly excludes comparing the target variable (which we want to predict) to observations of this variable at the place of interest - this is a prerequisite to using such observations to validate or falsify the model and/or the organizing principle, i.e. to hypothesis testing. In other words, consistency with local observations is only assessed during this validation or falsification phase, and is not imposed during the initial selection of plausible models.
This fundamental difference is often neither explicitly stated nor acknowledged (e.g. Dekker et al., 2011) and it motivated the present opinion paper. This should not, however, distract us from the fact that our proposed framework is a clear departure from traditional calibrated models. Nevertheless, the new behavioral modeling approach still faces the uncertainty issues that bedevil traditional models, namely the ones related to observational uncertainties (e.g. Kavetski et al. , 2006; Liu et. al, 2009), but now in the context of hypothesis testing. Our hope is that this new context will inspire new questions in this vast field.

\section{Potential of the new approach}

The behavioral modeling approach is based on explicit hypotheses about the functioning and directionality of evolution of whole ecosystems. Therefore, we believe it has great potential for the prediction of hydrologic change and much of the present paper argues along this line. Hereafter, we would like to discuss some additional promising aspects.

The proposed modeling framework represents a major step towards the building of models based on understanding rather than on calibration to detailed local observations. This goes to the heart of the philosophy adopted by the predictions in ungauged basins (PUB) initiative (Sivapalan, 2003). In this context, the organizing principles represent the crystallization of our understanding of how nature works and offer a new way to transfer knowledge of ecosystem functioning from one place to another.

Organizing principles encapsulate how small scale process interactions are related to the system evolution and response at some higher scales. They thus provide a link between the scale of prediction (e.g. the catchment scale) and the scale at which the relevant processes interact. As example, we can cite here the organizing principle proposed by Zehe et al. (2010). They propose maximum energy dissipation as a connection between worm burrow density and rapid water flow at the hillslope scale. In this sense, we can see that the investigation of organizing principles through virtual and realworld experiments, including controlled field or laboratory experiments, offers new perspectives towards mapping of relevant structures across scales.

The use of organizing principles also presents a new way of including more process understanding into hydrological models and for transferring understanding across different types of models. We can, for example, gain knowledge about the sensitivity of riparian ecosystems to water table depth from a simple physical model (see Ridolfi et al., 2006), translate it into an organizing principle (e.g., "maximization of resilience") and then use it to parameterize the vegetation cover (i.e. to identify the most likely vegetation state) in a more complicated hydrologic prediction model. Nicotina et al. (2011) use the principle of minimum energy expenditure, combined with a physical model, to identify equilibrium soil 
depths to be used in a rainfall-runoff model. In this sense, behavioral modeling has the potential to help unify (data-based) conceptual and physically-based modeling approaches.

Finally, a behavioral model can be viewed as a hypothesis about how a catchment ecosystem works. Since it provides quantitative predictions, the validity of the hypothesis can be tested by comparing the predictions against observed system responses (discharge, evaporation etc.). Our understanding advances, even if, and especially when, an organizing principle is proven to be false. This offers an important advantage over traditional models where the observed system response is used for model calibration and is difficult to use for further hypothesis testing, i.e., there is usually no generalizable hypothesis to test.

\section{Conclusions}

This paper has presented the rationale for a new behavioral modeling framework for hydrologic prediction that makes use of universal and time-invariant organizing principles to at least partially replace calibration to observed response data as in traditional models. Our hope is that this modeling framework will contribute to the development of a new generation of models that can be extrapolated in time and in space, and that open new perspectives for hypothesis testing and for unifying traditional conceptual and physically-based modeling approaches. It is a small step towards a new vision for hydrology: one in which there are less black-box parameters, where models are driven both by information about particular places and by fundamental understanding encapsulated in universal principles. It therefore heralds a new future for hydrology where hydrologic models are capable of more confidently predicting the response of a catchment to conditions that have not been experienced in the past, such as under climate or land-use change.

The key to this framework is to postulate that we can use organizing principles to identify the most probable behavior of a catchment ecosystem and the related most appropriate model structure and response. The proposed framework can be viewed as a generalization of optimality modeling, as the time-invariant organizing principles can either be derived from fundamental physical or biological laws (as in the case of several optimality hypotheses currently being explored), or from empirical laws that have extensively been shown to be time-invariant and to hold at many places and scales. The proposed framework aims at overcoming the need of observed data for model calibration and can be used as hypothesis testing tool when used in conjunction with available data.

There are, of course, an enormous number of open questions and to make progress in this direction, much further research is required: what types of organizing principles are useful for hydrologic prediction? Are they transferable, i.e. are they useful for predictive model development in many places? Can we classify catchments with the help of organizing principles? How can we know whether an ecosystem is in a stable state? How can we know how long it takes before a system reaches a new stable state?

Behavioral modeling should be viewed as a modeling technique, as a way of formulating modeling hypotheses and translating them into mathematical models (rather than as a "literal transcription" of what nature actually does). Unlike traditional approaches to modeling, where calibration rules the day, model building and model validation in the behavioral framework is really, in one way or the other, a hypothesis test. When a model constrained by an organizing principle fails to reproduce real-world observations, this in itself represents scientific progress as it helps eliminate inappropriate assumtions or model structures. Or, in other words, as Kull (2002) formulates it, "poor results (...) are not proof that optimality fails; they merely imply that the function to be maximized in a natural community remains undiscovered."

Building hydrologic models thus becomes a process of formulating hypotheses about the organization and structure of the landscape - hypotheses that will need to be tested by new observations and new field experiments. It will thus require an interdisciplinary research effort that brings together specialists from many different fields related to catchment and ecosystem functioning, motivated by both the desire to discover and test widely applicable organizing principles and by the need to make hydrologic predictions in specific places about future conditions.

Acknowledgements. This paper is a contribution of the NSFfunded project: Water Cycle Dynamic in a Changing Environment: Advancing Hydrologic Science through Synthesis (NSF Grant EAR-0636043, M. Sivapalan, PI). The work on this paper was supported by research grants awarded to BS by the Swiss National Science Foundation SNF and the German research foundation DFG, and by the Beatty Fellowship (of the UIUC Department of Geography) awarded to CJS. It was completed during a sabbatical stay by MS at the Delft University of Technology. This support is gratefully acknowledged. The paper benefited, in the early stages, from discussions with Patricia Saco and Hongyi Li and includes a figure (Fig. 1b) proposed by a discussion group on hydrologic change prediction during the 2010 Vienna Catchment Symposium. We would like to thank Keith Beven for his challenging discussion of our paper, which we invite the reader to consult on http://www.hydrol-earth-syst-sci-discuss.net/7/7779/2010. We also acknowledge the critical comments of an anonymous reviewer that helped sharpen our message.

Edited by: E. Zehe 


\section{References}

Band, L., Patterson, P., Nemani, R. and Running, S. W.: Forest ecosystem processes at the watershed scale: Incorporating hill slope hydrology, Agr. Forest Meteorol., 63, 93-126, doi:10.1016/0168-1923(93)90024-C, 1993.

Barnett, T., Pierce, D., Hidalgo, H., Bonfils, C., Santer, B., Das, T., Bala, G., Wood, A., Nozawa, T., Mirin, A., Cayan, D., and Dettinger, M.: Human-induced changes in the hydrology of the Western United States, Science, 319, 1080-1083, doi:10.1126/science.1152538, 2008.

Beven, K. J. and Binley, A.: The future of distributed models: model calibration and uncertainty prediction, Hydrol. Process., 6, 279-298, doi:10.1016/j.jhydrol.2005.07.007, 1992.

Beven, K. J. and Freer, J.: Equifinality, data assimilation, and uncertainty estimation in mechanistic modelling of complex environmental systems using the GLUE methodology, J. Hydrol., 249, 11-29, doi:10.1016/S0022-1694(01)00421-8, 2001.

Beven, K. J.: A manifesto for the equifinality thesis, J. Hydrol., 320, 18-36, doi:10.1002/hyp.3360060305, 2006.

Beven, K. J.: Preferential flows and travel time distributions: defining adequate hypothesis tests for hydrological process models Preface, Hydrol. Proc., 24, 1537-1547, doi:10.1002/hyp.7718, 2010a.

Black, P. E.: Watershed Hydrology, CRC Press, Boca Raton, Florida, 1986.

Blöschl, G. and Montanari, A.: Climate change impacts - throwing the dice?, Hydrol. Process., 24, 374-381, doi:10.1002/hyp.7574, 2010.

Borgogno, F., D’Odorico, P., Laio, F., and Ridolfi, L.: Mathematical models of vegetation pattern formation in ecohydrology, Rev. Geophys., 47, Rg1005, doi:10.1029/2007rg000256, 2009.

Brolsma, R. J. and Bierkens, M. F. P.: Groundwater-soil water-vegetation dynamics in a temperate forest ecosystem along a slope, Water Resour. Res., 43, W01414, doi:10.1029/2005WR004696, 2007.

Budyko, M. I.: Evaporation Under Natural Conditions, Gidrometeorizdat, St. Petersburg, Russia, 1984.

Caylor, K. K., Scanlon, T. M., and Rodriguez-Iturbe, I.: Ecohydrological optimization of pattern and processes in water-limited ecosystems: a trade-off-based hypothesis, Water Resour. Res., 45, W08407, doi:10.1029/2008WR007230, 2009.

Dekker, S. C., Vrugt, J. A. and Elkington, R. J.: Significant variation in vegetation characteristics and dynamics from ecohydrological optimality of net carbon profit, Ecohydrol., in press, doi:10.1002/eco.177, 2011.

Doherty, R., Kutzbach, J., Foley, J., and Pollard, D.: Fully coupled climate/dynamical vegetation model simulations over Northern Africa during the mid-Holocene, Clim. Dynam., 16, 561-573, doi: 10.1007/s003820000065, 2000.

Duan, Q., Soorshian, S., and Gupta, V. K.: Optimal use of the SCEUA global optimization method for calibrating watershed models, J. Hydrol., 158, 265-284, doi:10.1016/0022-1694(94)900574, 1994.

Eagleson, P.: Climate, soil, and vegetation, 6, dynamics of the annual water balance, Water Resour. Res., 14, 749-764, doi:10.1029/WR018i002p00325, 1978.

Eagleson, P. S.: Ecological optimality in water-limited natural soilvegetation systems, 1, theory and hypothesis, Water Resour. Res., 18, 325-340, doi:10.1029/WR018i002p00341, 1982.
Eagleson, P. S. and Tellers, T. E.: Ecological optimality in waterlimited natural soil-vegetation systems, 2, tests and applications, Water Resour. Res., 18, 341-354, doi:10.1029/2008wr007308, 1982.

Gerrits, A. M. J., Savenije, H. H. G., Veling, E. J. M., and Pfister, L.: Analytical derivation of the Budyko curve based on rainfall characteristics and a simple evaporation model, Water Resour. Res., 45, W04403, doi:10.1029/2008wr007308, 2009.

Gisiger, T.: Scale invariance in biology: coincidence or footprint of a universal mechanism?, Biol. Rev., 76, 161-209, doi:10.1017/S1464793101005607, 2001.

Grimm, V., Revilla, E., Berger, U., Jeltsch, F., Mooij, W. M., Railsback, S. F., Thulke, H. H., Weiner, J., Wiegand, T., and DeAngelis, D. L.: Pattern-oriented modeling of agent-based complex systems: lessons from ecology, Science, 310, 987-991, doi:10.1126/science.1116681, 2005.

Gupta, H. V., Beven, K. J., and Wagener, T.: Model calibration and uncertainty estimation, in: Encyclopedia of Hydrological Sciences, edited by: Anderson, M. G., vol. 3, Wiley, Chichester, 2015-2032, 2005.

Hornberger, G. M. and Spear, R. C.: Eutrophication in peel inlet - I. The problem-defining behavior and a mathematical model for the phosphorus scenario, Water Res., 14, 29-42, doi:10.1016/0043-1354(80)90039-1, 1980.

Horton, P., Schaefli, B., Hingray, B., Mezghani, A., and Musy, A.: Assessment of climate change impacts on Alpine discharge regimes with climate model uncertainty, Hydrol. Process., 20, 2091-2109, doi:10.1002/hyp.6197, 2006.

Huss, M., Farinotti, D., Bauder, A., and Funk, M.: Modelling runoff from highly glacierized alpine drainage basins in a changing climate, Hydrol. Process., 22, 3888-3902, doi:10.1002/hyp.7055, 2008.

Hwang, T., Band, L., and Hales, T. C.: Ecosystem processes at the watershed scale: extending optimality theory from plot to catchment, Water Resour. Res., 45, W11425, doi:10.1029/2009wr007775, 2009.

Kavetski, D., Kuczera, G., and Franks, S. W.: Bayesian analysis of input uncertainty in hydrological modeling: 1. Theory, Water Resour. Res., 42, W03407, doi:10.1029/2005WR004368, 2006.

Kleidon, A., Fraedrich, K., Kirk, E., and Lunkeit, F.: Maximum entropy production and the strength of boundary layer exchange in an atmospheric general circulation model, Geophys. Res. Lett., 33, L06706, doi:10.1029/2008GL035393, 2006.

Kleidon, A. and Schymanski, S. J.: Thermodynamics and optimality of the water budget on land: a review, Geophys. Res. Lett., 35, L20404, doi:10.1029/2005GL025373, 2008.

Kleidon, A., Malhi, Y., and Cox, P. M.: Maximum entropy production in environmental and ecological systems Introduction, Philos. T. R. Soc. B, 365, 1297-1302, doi:10.1098/rstb.2010.0018, 2010.

Kleinhans, M. G., Bierkens, M. F. P., and van der Perk, M.: HESS Opinions On the use of laboratory experimentation:"Hydrologists, bring out shovels and garden hoses and hit the dirt", Hydrol. Earth Syst. Sci., 14, 369-382, doi:10.5194/hess-14-369-2010, 2010.

Krebs, J. and Davies, N.: An Introduction to Behavioural Ecology, Blackwell Science, Oxford, 1993.

Kull, O.: Acclimation of photosynthesis in canopies: models and limitations, Oecologia, 133, 267-279, doi:10.1007/s00442-002- 
1042-1, 2002.

Kumar, P.: Variability, feedback, and cooperative process dynamics: elements of a unifying hydrologic theory, Geogr. Comp., 1, 1338-1360, doi:10.1111/j.1749-8198.2007.00068.x, 2007.

Lacey, G.: Stable channels in alluvium, minutes of the proceedings, Institution of Civil Engineers London, 229, 259292, doi:10.1680/imotp.1930.15592, 1930.

Levin, S. A.: The problem of pattern and scale in ecology, Ecology, 73, 1943-1967, doi:10.2307/1941447, 1992.

Levis, S., Bonan, G., Vertenstein, M., and Oleson, K.: The Community Land Models Dynamic Global Vegetation Model (CLMDGVM): technical description and users guide, NCAR/TN459+IA, Tech. rep., 2004.

Li, H.: Diagnostic Analysis of Runoff Partitioning at the Catchment Scale, Ph.D. thesis, Dept. of Civil and Environ. Eng., Univ. of Illinois at Urbana-Champaign, 2010.

Lin, G.-F. and Chen, L.-H.: Identification of homogeneous regions for regional frequency analysis using the self-organizing map, J. Hydrol., 324, 1-9, doi:10.1016/j.jhydrol.2005.09.009, 2006.

Liu, Y., Freer, J., Beven, K., and Matgen, P.: Towards a limits of acceptability approach to the calibration of hydrological models: Extending observation error, J. Hydrol., 367, 93-103, doi:10.1016/j.jhydrol.2009.01.016, 2009.

Mahmoud, M., Liu, Y., Hartmann, H., Stewart, S., Wagener, T., Semmens, D., Stewart, R., Gupta, H. V., Dominguez, D., Dominguez, F., Hulse, D., Letcher, R., Rashleigh, B., Smith, C., Street, R., Ticehurst, J., Twery, M., van Delden, H., Waldick, R., White, D., and Winter, L.: A formal framework for scenario development in support of environmental decision-making, Environ. Model. Softw., 24, 798-808, doi:10.1016/j.envsoft.2008.11.010, 2009.

Marani, M., Belluco, E., Ferrari, S., Silvestri, S., D’Alpaos, A., Lanzoni, S., Feola, A., and Rinaldo, A.: Analysis, synthesis and modelling of high-resolution observations of salt-marsh ecogeomorphological patterns in the Venice lagoon, Estuar. Coast. Shelf S., 69, 414-426, doi:10.1016/j.ecss.2006.05.021, 2006a.

Marani, M., Silvestri, S., Belluco, E., Ursino, N., Comerlati, A., Tosatto, O., and Putti, M.: Spatial organization and ecohydrological interactions in oxygen-limited vegetation ecosystems, Water Resour. Res., 42, W05d06, doi:10.1029/2005wr004582, 2006 b.

McDonnell, J., Sivapalan, M., Vach, K., Dunn, S., Grant, G., Haggerty, R., Hinz, C., Hooper, R., Kirchner, K., Roderick, M. L., Selker, J., and Weiler, M.: Moving beyond heterogeneity and process complexity: a new vision for watershed hydrology, Water Resour. Res., 43, W07301, doi:10.1029/2006WR005467, 2007.

Miles, J., Cummins, R. P., French, D. D., Gardner, S., Orr, J. L., and Shewry, M. C.: Landscape sensitivity: an ecological view, Catena, 42, 125-141, doi:10.1016/S0341-8162(00)00135$1,2001$.

Nicotina, L., Tarboton, D., Tesfa, T., and Rinaldo, A.: Hydrologic controls on equilibrium soil depths, Water Resour. Res., doi:10.1029/2010WR009538, in press, 2011.

Ozawa, H., Ohmura, A., Lorenz, R. D., and Pujol, T.: The second law of thermodynamics and the global climate system: a review of the maximum entropy production principle, Rev. Geophys., 41, 1018, doi:10.1029/2002RG000113, 2003.

Paik, K. and Kumar, P.: Optimality approaches to describe characteristic fluvial patterns on landscapes, Philos. T. R. Soc. B, 365,
1387-1395, doi:10.1098/rstb.2009.0303, 2010.

Paola, C., Foufoula-Georgiou, E., Dietrich, W. E., Hondzo, M., Mohrig, D., Parker, G., Power, M. E., Rodriguez-Iturbe, I., Voller, V., and Wilcock, P.: Toward a unified science of the Earth's surface: opportunities for synthesis among hydrology, geomorphology, geochemistry, and ecology, Water Resour. Res., 42, W03S10, doi:10.1029/2005WR004336, 2006.

Polderman, J. and Willems, J.: Introduction to Mathematical Systems Theory: A Behavioral Approach, Springer, New York, 1998.

Porporato, A., Laio, F., Ridolfi, L., and Rodriguez-Iturbe, I.: Plants in water-controlled ecosystems: active role in hydrologic processes and response to water stress: III. Vegetation water stress, Adv. Water Resour., 24, 725-744, doi:10.1016/S03091708(01)00004-5, 2001.

Ridolfi, L., D'Odorico, P., and Laio, F.: Effect of vegetationwater table feedbacks on the stability and resilience of plant ecosystems, Water Resour. Res., 42, W01201, doi:10.1029/2005wr004444, 2006.

Rietkerk, M. and van de Koppel, J.: Regular pattern formation in real ecosystems, Trend Ecol. Evol., 23, 169-175, doi:10.1016/j.tree.2007.10.013, 2008.

Rinaldo, A., Rodriguez-Iturbe, I., Rigon, R., Bras, R. L., Ijjaszvasquez, E., and Marani, A.: Minimum energy and fractal structures of drainage networks, Water Resour. Res., 28, 2183-2195, doi:10.1029/92WR00801, 1992.

Rinaldo, A., Banavar, J. R., and Maritan, A.: Trees, networks, and hydrology, Water Resour. Res., 42, W06D07, doi:10.1029/2005WR004108, 2006.

Rodriguez-Iturbe, I., D’Odorico, P., Porporato, A., and Ridolfi, L.: On the spatial and temporal links between vegetation, climate, and soil moisture, Water Resour. Res., 35, 3709-3722, doi:10.1029/91WR03034, 1999.

Rodriguez-Iturbe, I., Rinaldo, A., Rigon, R., Bras, R. L., Marani, A., and Ijjaszvasquez, E.: Energy-dissipation, runoff production, and the 3-dimensional structure of river basins, Water Resour. Res., 28, 1095-1103, doi:10.1029/92GL00938, 1992a.

Rodriguez-Iturbe, I., Rinaldo, A., Rigon, R., Bras, R. L., Marani, A., and Ijjasz-Vasquez, E. J.: Fractal structure as least energy patterns: the case of river networks, Geophys. Rev. Lett., 19, 889-892, doi:10.1029/1999WR900255, 1992b.

Rodriguez-Iturbe, I., D’Odorico, P., Laio, F., Ridolfi, L., and Stefania Tamea, S.: Challenges in humid land ecohydrology: interactions of water table and unsaturated zone with climate, soil, and vegetation, Water Resour. Res., 43, W09301, doi:10.1029/2007WR006073, 2007.

Saco, P. M., Willgoose, G. R., and Hancock, G. R.: Ecogeomorphology of banded vegetation patterns in arid and semi-arid regions, Hydrol. Earth Syst. Sci., 11, 1717-1730, doi:10.5194/hess-11-1717-2007, 2007.

Savenije, H. H. G.: The width of a bankfull channel; Lacey's formula explained, J. Hydrol., 276, 176-183, doi:10.1016/s00221694(03)00069-6, 2003.

Schaefli, B., Hingray, B., and Musy, A.: Climate change and hydropower production in the Swiss Alps: quantification of potential impacts and related modelling uncertainties, Hydrol. Earth Syst. Sci., 11, 1191-1205, doi:10.5194/hess-11-11912007, 2007. 
Schaefli, B. and Zehe, E.: Hydrological model performance and parameter estimation in the wavelet-domain, Hydrol. Earth Syst. Sci., 13, 1921-1936, doi:10.5194/hess-13-1921-2009, 2009.

Schymanski, S. J.: Transpiration as the Leak in the Carbon Factory: A Model of Self-Optimising Vegetation, Ph.D. thesis, University of Western Australia, Perth, Australia, 2007.

Schymanski, S., Roderick, M., Sivapalan, M., Hutley, L., and Beringer, J.: A test of the optimality approach to modelling canopy properties and $\mathrm{CO}_{2}$ uptake by natural vegetation, Plant Cell Environ., 30, 1586-1598, doi:10.1111/j.13653040.2007.01728.x, 2007.

Schymanski, S. J., Roderick, M. L., Sivapalan, M., Hutley, L. B., and Beringer, J.: A canopy scale test of the optimal water use hypothesis, Plant Cell \& Environment, 31, 97-111, doi:10.1111/j.1365-3040.2007.01740.x, 2008a.

Schymanski, S. J., Sivapalan, M., Roderick, M. L., Beringer, J., and Hutley, L. B.: An optimality-based model of the coupled soil moisture and root dynamics, Hydrol. Earth Syst. Sci., 12, 913 932, doi:10.5194/hess-12-913-2008, 2008b.

Schymanski, S. J., Kleidon, A., and Roderick, M. L.: Ecohydrological optimality, in: Encyclopedia of Hydrological Sciences, edited by: Anderson, M. G., vol. 1, Wiley, Chichester, 2009a.

Schymanski, S. J., Sivapalan, M., Roderick, M. L., Hutley, L. B., and Beringer, J.: An optimality-based model of the dynamic feedbacks between natural vegetation and the water balance, Water Resour. Res., 45, W01412, doi:10.1029/2008wr006841, 2009b.

Sidle, R. C. and Onda, Y.: Hydrogeomorphology: overview of an emerging science, Hydrol. Process., 18, 597-602, doi:10.1002/hyp.1360, 2004.

Sivapalan, M.: Prediction in ungauged basins: a grand challenge for theoretical hydrology, Hydrol. Process., 17, 3163-3170, doi:10.1002/hyp.5155, 2003.

Sivapalan, M.: Pattern, process and function: elements of a unified theory of hydrology at the catchment scale, in: Encyclopedia of Hydrological Sciences, edited by: Anderson, M. G., vol. 1, Wiley, Chichester, 193-220, 2005.
Stonestrom, D. A., Scanlon, B. R., and Zhang, L.: Introduction to special section on impacts of land use change on water resources, Water Resour. Res., 45, W00A00, doi:10.1029/2009WR007937, 2009.

Tague, C. and Band, L.: RHESSys: Regional hydroecologic simulation system: an object-oriented approach to spatially distributed modeling of carbon, water and nutrient cycling, Earth Int., 8, 19, doi:10.1175/10873562(2004)8<1:RRHSSO > 2.0.CO;2, 2004.

Thomas, M.: Landscape sensitivity in time and space - an introduction, Catena, 42, 83-98, doi:10.1016/S0341-8162(00)00133-8, 2001.

Usher, M. B.: Landscape sensitivity: from theory to practice, Catena, 42, 375-383, doi:10.1016/S0341-8162(00)00148X, 2001.

Vrugt, J. A., van Belle, J., and Bouten, W.: Pareto front analysis of flight time and energy use in long-distance bird migration, J. Avian Biol., 38, 432-442, doi:10.1111/j.2007.09088857.03909.x, 2007.

Wagener, T., Sivapalan, M., Troch, P. A., and Woods, R.: Catchment classification and hydrologic similarity, Geogr. Comp., 1, 901931, doi:10.1111/j.1749-8198.2007.00039.x, 2007.

Wagener, T., Sivapalan, M., Troch, P. A., McGlynn, B. L., Harman, C. J., Gupta, H. V., Kumar, P., Rao, P. S. C., Basu, N. B., and Wilson, J. S.: The future of hydrology: an evolving science for a changing world, Water Resour. Res., 46, W05301, doi:10.1029/2009WR008906, 2010.

Wong, T. S. W.: How nature uses overland flow regime to maximize equilibrium detention storage and flood attenuation, Hydrol. Process., 22(26), 5004-5012, doi:10.1002/hyp.7120, 2008.

Zehe, E., Blume, T., and Bloschl, G.: The principle of "maximum energy dissipation": a novel thermodynamic perspective on rapid water flow in connected soil structures, Philos. T. R. Soc. B, 365 , 1377-1386, doi:10.1098/rstb.2009.0308, 2010.

Zierl, B. and Bugmann, H.: Global change impacts on hydrological processes in Alpine catchments, Water Resour. Res., 41, W02028, doi:10.1029/2004WR003447, 2005. 